\title{
Discrepancies between urinary symptoms assessment and objective bladder dysfunctions in multiple sclerosis
}

\author{
Shalom Haggiag ${ }^{1,4^{*}}$, Giovanni Bolla ${ }^{2}$, Orietta Picconi ${ }^{*^{*}}$, Simonetta Galgani ${ }^{1}$ and Claudio Gasperini ${ }^{1}$
}

\begin{abstract}
Objective: To assess the association between objective bladder function parameters in relation to urinary symptoms, and to analyze the sensitivity and specificity of subjective urinary symptom-assessment in predicting objective bladder dysfunction in a multiple sclerosis (MS) population.
\end{abstract}

Methods: Consecutive MS patients with Expanded Disability Status Score (EDSS) $\leq 7.0$ were included in this prospective study. In a single visit, patients were evaluated for the presence of urinary symptoms, then assessed for the following urological parameters: maximum urinary flow rate (Qmax), postvoid residual urine volume (PVR), and detrusor sphincter dyssinergia (DSD).

Results: One hundred nine subjects were included with a mean disease duration of $12.5 \pm 8.7$ years, $90.8 \%$ had a relapsing-remitting course; the mean EDSS score was $2.6 \pm 1.7$. Overall, $53.5 \%$ complained of at least one urinary symptom, and the most reported one was urgency (40.7\%), followed by frequency (15.7\%) and incomplete emptying (12.0\%). Abnormal values were found for Qmax in 34.9\%, for PVR in 40.4\% of participants; DSD was diagnosed in 33.9\% of the cases. Only Qmax was found negatively associated with the EDSS score $(p=0.007)$, but no other association was observed. The presence of urinary symptoms was poor predictor of bladder dysfunction, urgency among the others showed relatively higher predicting value.

Conclusions: Subjective urinary symptoms assessment failed in predicting bladder function. Our results confirmed the value of objective urological assessment in patients with MS, irrespective of the presence of urinary symptoms.

Keywords: Multiple sclerosis, Bladder dysfunction, Urinary symptoms

\section{Introduction}

Urinary disturbances may be a presenting sign in up to $14 \%$ of newly diagnosed Multiple Sclerosis (MS) patients [1], and is a major problem for over $50 \%$ of patients at some point throughout their disease course [2]. Urinary symptoms in MS can be grouped into three general syndromes: a) detrusor hyperreflexia - decreased storage capacity; b) incomplete emptying - hypotonic detrusor muscles; c) detrusor sphincter dyssynergia (DSD) - lack of detrusor/sphincter coordination.

Under-recognition of bladder dysfunction may have implications on quality of care given that effective therapies

\footnotetext{
* Correspondence: Lvshalom@hotmail.com;

'MS Clinical Centre, San Camillo-Forlanini Hospital, Rome, Italy

${ }^{3}$ Opera S.R.L. CRO, Genoa, Italy

Full list of author information is available at the end of the article
}

are available in preventing urinary complications and in improving patient's quality of life $[3,4]$. Few and heterogeneous studies have investigated the relationship between subjective urinary complaints and objective urological parameters in MS patients, reaching different conclusions [3, 5-9]. Is a routinary evaluation of urinary symptoms sufficient to exclude the presence of bladder dysfunction in patients with MS? To address this question, we designed a prospective study with the following objectives: 1 ) To assess the association between objective bladder function parameters in relation to urinary complaints; 2 ) to analyze the sensitivity and specificity of subjective urinary symptomassessment in predicting objective bladder dysfunction in patients with MS. 


\section{Methods}

\section{Subjects}

During a period of 1 year we have been prospectively recruiting consecutive patients with MS [10] from our MS Centre, San Camillo-Forlanini Hospital of Rome, Italy. Patients with the following features were excluded: 1) Expanded Disability Status Score (EDSS) score $>7.0 ; 2$ ) primary progressive course; 3) any conditions adversely affecting bladder function, other than MS; 4) presence of non-sterile urine culture; 5) any symptomatic treatments for bladder dysfunction; 6) current participation in other clinical trials.

During a single scheduled visit, through a face-to-face unstructured interview, patients were asked about the presence of urinary symptoms, as part of the bowel/bladder Functional System (FS) score, including urgency, frequency, hesitancy, urge incontinence and incomplete emptying. The symptoms were considered as present or absent, irrespective of severity or duration of the symptoms. The patient's clinical status has been assessed by EDSS.

\section{Assessment of bladder function}

On the same day, all the patients were evaluated by an experienced urologist (G.B.) for the following urological parameters: maximum urinary flow rate (Qmax), postvoid residual urine volume (PVR), and detrusor sphincter dyssinergia (DSD). Qmax measurement was obtained by a computerized uroflowmeter (normal values $>15 \mathrm{ml} / \mathrm{s}$ ). PVR was indirectly measured by ultrasound scan (normal values $<60 \mathrm{ml}$ ). DSD, as a loss of coordinated action of the detrusor and external sphincter muscles, was diagnosed on the basis of a combined assessment of urinary flow recordings and external urethral sphincter Electromyography (EMG) with surface electrodes $[11,12]$.

\section{Statistical analysis}

Only subjects with fully completed data were considered evaluable for the statistical analysis. All values are presented as mean $\pm \mathrm{SD}$ or median (interquantile range) for continuous variables and as a number of subjects (percentage) for categorical variables. Comparisons were performed by means of analysis of variance for mean values and of Chisquare test. In order to identify the variables associated with bladder dysfunction, a logistic regression analysis was performed, considering the presence of abnormal urological parameters (Qmax, PVR, DSD) as outcome of the dependent variable and regressors were the presence of urinary symptoms and clinical parameters. Sensitivity and specificity of urinary symptoms for bladder dysfunction detection were calculated on a per-patient basis.

\section{Results}

Of the 141 patients screened, 109 (77.3\%) met the study criteria and completed the protocol assessments (Table 1).
Sample mean age was $44.6 \pm 10.1$ years, 80 (73.4\%) subjects were females, the mean disease duration was $12.5 \pm$ 8.7 years, 99 (90.8\%) had a relapsing-remitting (RR) course, 10 (9.2\%) had a secondary-progressive (SP) course; mean EDSS score was equal to $2.6 \pm 1.7$. Most of the patients were under immunomodulatory agents $(N=69$ patients, 63.3\%), a minority under immunosuppressive agents $(n=6,5.5 \%)$, and a third were untreated $(n=34$ patients, $31.2 \%)$.

Fifty-eight patients (53.5\%) complained of at least one urinary symptom, of these $65.5 \%$ one symptom, $24.1 \%$ two symptoms, while $10.4 \%$ complained of at least three symptoms. The frequency of specific urinary symptoms was as follows: urgency (40.7\%), frequency (15.7\%), incomplete emptying (12.0\%), hesitancy (8.3\%), urge incontinence (3.7\%). No significant differences were observed between females and males patients in the frequency of urinary symptoms. Overall the mean Qmax value was $19.8 \pm$ $9.7 \mathrm{ml} / \mathrm{s}$, it was abnormal in $34.9 \%$ of subjects. The mean PVR was $66.9 \pm 82.1 \mathrm{ml}$ abnormal in $40.4 \%$ of participants. No significant differences were found for Qmax and PVR between females and males patients. Then, DSD was diagnosed in 37 subjects (33.9\%), 32 (40.2\%) females and 4 males patients $(14.8 \% ; p=0.016)$.

By linear regression analysis, as expected both age ( $p$ $<0.001)$ and disease duration $(p<0.001)$ were positively associated with EDSS score. Whereas, when considering the urological parameters, only Qmax was found negatively associated with EDSS score $(p=0.007)$, and no other association was observed. Furthermore, the presence of urinary symptoms was poor predictor of objective bladder dysfunction, as assessed by the diagnostic procedures employed in our study. Overall urgency is what showed higher, albeit small, values of both sensitivity and specificity in predicting Qmax values (57.89; 69.01), PVR (50.0; 66.15) and DSD (36.99; 52.78). The other symptoms generally showed high specificity but with very low sensitivity (Table 2 ).

\section{Discussion}

We conducted a prospective study in a large MS population, not undergoing symptomatic treatment for urinary disturbances (to obtain unbiased evaluations and a more homogeneous sample possible), evaluating urinary symptoms and objective bladder dysfunction parameters. Our results indicated that a routine urinary symptoms assessment has a poor predictive value of objective bladder dysfunction in patients with MS. In our population over half of patients experienced at least one urinary symptom, and only about one third of patients showed at least one abnormal urological parameter. Urgency, more of the other symptoms, showed to be modestly sensitive and specific in predicting the presence of abnormal urological parameters, whereas the other symptoms showed no significant predictive value. This agrees with the 
Table 1 Demographic, clinical and urological features of the patients with MS

\begin{tabular}{|c|c|c|c|c|c|}
\hline & Ranges & Totals & Women & Men & $p$ value \\
\hline Sex, N (\%) & & $109(100.0)$ & $80(73.4)$ & $29(26.6)$ & \\
\hline Age, mean $\pm S D$ & $24-67$ & $44,6 \pm 10,1$ & $43,8 \pm 9,0$ & $44,3 \pm 10,5$ & NS \\
\hline RRMS, N (\%) & & $99(90.8)$ & $73(53.4)$ & $26(89.6)$ & NS \\
\hline SPMS, $N(\%)$ & & $10(9.2)$ & $7(8.7)$ & $3(10.3)$ & NS \\
\hline $\mathrm{EDSS}$, mean $\pm \mathrm{SD}$ & $0.0-7.0$ & $2,6 \pm 1,7$ & $2,5 \pm 1,7$ & $2,6 \pm 1,8$ & NS \\
\hline Disease duration $(\mathrm{y})$, mean $\pm \mathrm{SD}$ & $0.9-43$ & $12,5 \pm 8,7$ & $12,6 \pm 8,8$ & $11,3 \pm 8,8$ & NS \\
\hline Immunomodulatory treatment, $N(\%)$ & & $69(63.3)$ & $50(62.5)$ & $19(65.5)$ & NS \\
\hline Immunosuppressive treatment, $N(\%)$ & & $6(5.5)$ & $5(6.2)$ & $1(3.5)$ & NS \\
\hline Untreated, $N(\%)$ & & $34(31.2)$ & $25(31.3)$ & $9(31.0)$ & NS \\
\hline Patients with $\geq 1$ urinary symptom, N (\%) & & $57(52.3)$ & $39(48.7)$ & $18(62.1)$ & NS \\
\hline 1 symptom & & $38(65.5)$ & $24(61.5)$ & $14(77.7)$ & NS \\
\hline 2 symptoms & & $15(25.9)$ & $11(27.5)$ & $4(22.2)$ & NS \\
\hline$\geq 3$ symptoms & & $5(8.6)$ & $5(12.5)$ & $0(0.0)$ & NS \\
\hline Urgency & & $44(40.4)$ & $32(40.0)$ & $12(41.2)$ & NS \\
\hline Frequency & & $17(15.6)$ & $13(16.2)$ & $4(13.8)$ & NS \\
\hline Incomplete emptying & & $13(11.9)$ & $10(12.5)$ & $3(10.3)$ & NS \\
\hline Hesitancy & & $9(8.3)$ & $8(10.0)$ & $1(5.5)$ & NS \\
\hline Urge incontinence & & $3(3.7)$ & $3(3.7)$ & $1(3.5)$ & NS \\
\hline Qmax, mean \pm SD & $0-65$ & $19.8 \pm 11.2$ & $21.1 \pm 11.3$ & $17.0 \pm 7.1$ & 0.029 \\
\hline Abnormal values (<15 ml/s), N (\%) & & $38(34.9)$ & $26(32.5)$ & $12(41.4)$ & NS \\
\hline$P V R$, mean $\pm S D$ & $0-1000$ & $66.6 \pm 82.1$ & $64.6 \pm 85.1$ & $73.6 \pm 75.1$ & NS \\
\hline Abnormal values $(<15 \mathrm{ml} / \mathrm{s}), N(\%)$ & & $44(40.4)$ & $28(35.0)$ & $16(55.2)$ & NS \\
\hline DSD, N (\%) & & 37 (33.9) & $32(40.0)$ & $5(17.2)$ & 0.016 \\
\hline
\end{tabular}

Abbreviations: RRMS Relapsing-Remitting Multiple Sclerosis, SPMS Secondary Progressive Multiple Sclerosis, EDSS Expanded Disability Status Scale, Qmax maximum urinary flow rate, $P V R$ postvoid residual urine volume, DSD detrusor sphincter dyssinergia

findings of a large MS population study, where subjective assessments by bladder FS score and Guy's Neurological Disability Scale bladder function score were not predictive of a clinically relevant postmicturition volume [13]. Similarly, in a prospective study of symptomatic MS patients, no significant correlation was found between clinical features and urodynamic patterns [5]. Instead, Betts et al. showed that MS patients with irritative bladder symptoms and lower limb pyramidal involvement were highly likely to have detrusor hyperreflexia, such as to make unnecessary to run the urodynamic study to choose the anticholinergic therapy [7]; similarly Araki et al. found that urinary irritative symptoms reflect the disease severity [9]. Betts et al. reported a linear progression of residual urine volume with bladder FS score, and suggested to perform the post-void urine volume measurement only in patients with significant disability [7].

In our population, possible explanations for the lack of predictive value of urinary assessments in detecting bladder dysfunction are several. First, the modality of data collection of urinary symptoms may be questionable. Although our choice to adopt an unstructured interview for the collection of major urinary symptoms was intended to reproduce clinical routine practice, the use of validated questionnaires would have allowed a more homogenous and reliable assessment [14]. Second, the selection of the objective urological parameters adopted in our study may be questionable as compared to more reliable and invasive diagnostic procedures, such as simultaneous recording of intravesical pressure and needle sphincter electromyography [12]. Third, the co-existence of common impairments such as changes in cognition, fatigue, and constipation may impair the patient's awareness of the symptom itself. Furthermore, physical disability may impair the patient's urinary control, without having a direct effect on bladder function.

So far international management guidelines for urinary disturbances have been developed [15, 16], but are not specific for the MS population. The International Scientific Committee of the $5^{\text {th }}$ International Consultation on Incontinence on 2012 has formulated general recommendations for the diagnosis of neurogenic lower urinary tract dysfunction (NLUTD): a) patients with neurologic disease known to be associated with NLUTD should be evaluated 
Table 2 Sensitivity and specificity of urinary symptoms in predicting urological parameters in patients with MS

\begin{tabular}{lll}
\hline Symptoms vs. Qmax & Sensitivity & Specificity \\
\hline Urgency & 57,89 & 69,01 \\
Frequency & 26,32 & 90,14 \\
Hesitancy & 15,79 & 95,77 \\
Incomplete emptying & 13,16 & 88,73 \\
Urge incontinence & 10,53 & 100,00 \\
Symptoms vs. PVR & & \\
Urgency & 50,00 & 66,15 \\
Frequency & 18,18 & 86,15 \\
$\quad$ Hesitancy & 9,09 & 92,31 \\
Incomplete emptying & 13,64 & 89,23 \\
Urge incontinence & 2,27 & 95,38 \\
Symptoms vs. DSD & & \\
Urgency & 36,99 & 52,78 \\
Frequency & 13,70 & 80,56 \\
Hesitancy & 8,33 & 91,78 \\
Incomplete emptying & 8,33 & 86,30 \\
Urge incontinence & 0,00 & 94,52 \\
\hline
\end{tabular}

for the presence of lower urinary tract symptoms; b) urodynamic tests should selectively be employed to supplement clinical assessment in determining management in NLUTD; c) sphincter EMG can be valuable in the diagnosis of patients with neurologic bladder dysfunction and can be considered as a diagnostic method in patients with NLUTD and neurologic urinary incontinence [15]. Several European national panels have published their own MS management consensus [17-20], although, they are mainly based on studies with low levels of evidence. While all groups advocate urological evaluation of symptomatic patients, the recommended approaches for asymptomatic patients are partially divergent and do not reach consensus [17-20].

\section{Conclusions}

In our MS population a routine subjective urinary symptoms assessment poorly correlated with objective bladder dysfunctions. Urgency resulted as the most predictive symptom, albeit modestly. Our data, in line with previous studies $[5,13]$, suggest that in patients with MS objective bladder evaluation, irrespective of subjective urinary symptoms, may contribute to a more complete and reliable assessment of patient's disability. Given the feasibility of these non-invasive urological evaluations, we recommend making that objective assessment of bladder function become standard considerations in the evaluation of patients with MS, regardless of the presence of subjective urinary symptoms.

\section{Acknowledgements}

We would like to thank the nursing staff for their kind assistance in helping conduct the study.

\section{Funding}

This research received no specific grant from any funding agency in the public, commercial, or not-for-profit sectors.

\section{Availability of data and materials}

The datasets collected and/or analyzed during the current study are available from the corresponding author on reasonable request.

\section{Authors' contributions}

SH, GB, SG, CG conception and design of the work. SH, OP data collection. $\mathrm{SH}, \mathrm{OP}, \mathrm{GB}$ data analysis and interpretation. SH drafting the article. All the authors critical revision of the article. All the authors final approval of the version to be published.

\section{Competing interests}

The authors declare that they have no competing interests.

\section{Consent for publication}

Not applicable

\section{Ethics approval and consent to participate}

The study underwent on approval of local Ethical Committee and all patients have given written informed consent to participate, as well as processing personal data authorization.

\section{Publisher's Note}

Springer Nature remains neutral with regard to jurisdictional claims in published maps and institutional affiliations.

\section{Author details}

${ }^{1}$ MS Clinical Centre, San Camillo-Forlanini Hospital, Rome, Italy. ${ }^{2}$ Urology Department, San Camillo-Forlanini Hospital, Rome, Italy. ${ }^{3}$ Opera S.R.L. CRO, Genoa, Italy. ${ }^{4}$ Centro Sclerosi Multipla, Azienda Ospedaliera San

Camillo-Forlanini, Circonvallazione Gianicolense 87, 00152 Rome, Italy.

Received: 30 January 2017 Accepted: 10 May 2017

Published online: 07 August 2017

\section{References}

1. Fowler JF. Neurology of bladder, bowel, and sexual dysfunction. Butterworth-Heinemann Medical: Woburn, MA; 1999.

2. Miller H, Simpson CA, Yeates WK. Bladder dysfunction in multiple sclerosis. Br Med J. 1965;1(5445):1265-9.

3. DasGupta R, Fowler CJ. Bladder, bowel and sexual dysfunction in multiple sclerosis: management strategies. Drugs. 2003;63(2):153-66.

4. Kalsi V, Fowler CJ. Therapy insight: bladder dysfunction associated with multiple sclerosis. Nat Clin Pract Urol. 2005;2(10):492-501.

5. Gallien P, Robineau S, Nicolas B, Le Bot MP, Brissot R, Verin M. Vesicourethral dysfunction and urodynamic findings in multiple sclerosis: a study of 149 cases. Arch Phys Med Rehabil. 1998;79(3):255-7.

6. Kirchhof $\mathrm{K}$, Fowler $\mathrm{CJ}$. The value of the kurtzke functional systems scales in predicting incomplete bladder emptying. Spinal Cord. 2000;38(7):409-13.

7. Betts CD, D'Mellow MT, Fowler CJ. Urinary symptoms and the neurological features of bladder dysfunction in multiple sclerosis. J Neurol Neurosurg Psychiatry. 1993;56(3):245-50.

8. Litwiller SE, Frohman EM, Zimmern PE. Multiple sclerosis and the urologist. Urol. 1999;161(3):743-57.

9. Araki I, Matsui M, Ozawa K, et al. Relationship between urinary symptoms and disease-related parameters in multiple sclerosis. J Neurol. 2002;249(8): 1010-5.

10. McDonald WI, Compston A, Edan G, et al. Recommended diagnostic criteria for multiple sclerosis: guidelines from the international panel on the diagnosis of multiple sclerosis. Ann Neurol. 2001;50(1):121-7.

11. Amarenco $G$, de Sèze $M$, Ruffion $A$, et al. Clinical and urodynamic evaluations of urinary disorders in multiple sclerosis. Ann Phys Rehabil Med. 2014;57(5):277-87.

12. Stoffel JT. Detrusor sphincter dyssynergia: a review of physiology, diagnosis, and treatment strategies. Transl Androl Urol. 2016;5(1):127-35.

13. Kragt JJ, Hoogervorst EL, Uitdehaag BM, Polman CH. Relation between objective and subjective measures of bladder dysfunction in multiple sclerosis. Neurology. 2004;63(9):1716-8. 
14. Aharony SM, Lam O, Corcos J. Evaluation of lower urinary tract symptoms in multiple sclerosis patients: review of the literature and current guidelines. Can Urol Assoc J. 2017;11(1-2):61-4.

15. Abrams PCL, Khoury S, Wein A. Incontinence. 5th ed. Amhem: European association of urology; 2013.

16. Groen J, Pannek J, Castro Diaz D, et al. Summary of European Association of Urology (EAU) guidelines on neuro-urology. Eur Urol. 2016;69(2):324-33.

17. Ghezzi A, Carone R, Del Popolo G, et al. Recommendations for the management of urinary disorders in multiple sclerosis: a consensus of the Italian Multiple Sclerosis Study Group. Neurol Sci. 2011;32(6):1223-31.

18. De Ridder D, Van Der Aa F, Debruyne J, et al. Consensus guidelines on the neurologist's role in the management of neurogenic lower urinary tract dysfunction in multiple sclerosis. Clin Neurol Neurosurg. 2013;115(10):2033-40.

19. Amarenco G, Chartier-Kastler E, Denys $P$, et al. First-line urological evaluation in multiple sclerosis: validation of a specific decision-making algorithm. Mult Scler. 2013;19(14):1931-7.

20. de Sèze M, Ruffion A, Denys $P$, et al. The neurogenic bladder in multiple sclerosis: review of the literature and proposal of management guidelines. Mult Scler. 2007;13(7):915-28.

\section{Submit your next manuscript to BioMed Central} and we will help you at every step:

- We accept pre-submission inquiries

- Our selector tool helps you to find the most relevant journal

- We provide round the clock customer support

- Convenient online submission

- Thorough peer review

- Inclusion in PubMed and all major indexing services

- Maximum visibility for your research

Submit your manuscript at www.biomedcentral.com/submit

Biomed Central 